\title{
APPLICATION OF CAPITAL ASSET PRICING MODEL BASED ON THE SECURITY MARKET LINE
}

\author{
Dr. Ritika Sinha
}

\begin{abstract}
The CAPM is a model for pricing an individual security (asset) or a portfolio. For individual security perspective, we made use of the security market line (SML) and its relation to expected return and systematic risk (beta) to show how the market must price individual securities in relation to their security risk class. The SML enables us to calculate the reward-to-risk ratio for any security in relation to that of the overall market., Securities with higher returns are considered to be undervalued and attractive for buy. The below normal expected return yielding securities are considered to be overvalued and suitable for sale. SML is found to be the best tool for capital asset pricing analysis as it gives that a clear signal of overpriced and underpriced. In this paper we attempt to compare expected return estimates, which are implicit in share prices, growth rates, and the dividend growth model, with expected return estimates from the CAPM. We use the National Stock Exchange as the market benchmark for computing betas for the CAPM, and S\&P CNX NIFTY Stocks for computing betas for the CAPM. Our sample comprises S\&P CNX NIFTY companies over the period 2005 - 2010. In this paper five years nifty stocks of 10 companies has been taken for testing relevance of CAPM analysis. The main objective of this paper is to test the CAPM model and to use the CAPM for the selection of securities and portfolios using SML.
\end{abstract}

\section{Introduction}

The Capital Asset Pricing Model (CAPM) is used in finance to determine a theoretically appropriate required rate of return (and thus the price, if expected cash flows can be estimated) of an asset, if that asset is to be added to an already well-diversified portfolio, given that asset's non-diversifiable risk. The CAPM formula takes into account the asset's sensitivity to non-diversifiable risk (also known as systematic risk or market risk), in a number often referred to as beta (â) in the financial industry, as well as the expected return of the market and the expected return of a theoretical risk-free asset. The model was introduced by Jack Treynor, William Sharpe, John Lintner and Jan Mossin independently, building on the earlier work of Harry Markowitz on diversification and modern portfolio theory. Sharpe received the Nobel Memorial Prize in Economics (jointly with Harry Markowitz and Merton Miller) for this contribution to the field of financial economics.

The market reward-to-risk ratio is effectively the market risk premium and by rearranging the above equation and solving for $E(R i)$, we obtain the Capital Asset Pricing Model

\section{Asset pricing}

Once the expected return, $E(R i)$, is calculated using CAPM, the future cash flows of the asset can be discounted to their present value using this rate $(E(R i))$, to establish the correct price for the asset. In theory, therefore, an asset is correctly priced when its observed price is the same as its value

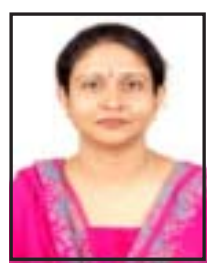

\section{Dr. RITIKA SINHA}

Assistant Professor, Bangalore University Bangalore. 
calculated using the CAPM derived discount rate. If the observed price is higher than the valuation, then the asset is overvalued (and undervalued when the observed price is below the CAPM valuation).

\section{Asset-specific required return}

The CAPM returns the asset-appropriate required return or discount rate - i.e. the rate at which future cash flows produced by the asset should be discounted given that asset's relative riskiness. Betas exceeding one signify more than average "riskiness"; betas below one indicate lower than average. Thus a more risky stock will have a higher beta and will be discounted at a higher rate; less sensitive stocks will have lower betas and be discounted at a lower rate. The CAPM is consistent with intuition - investors (should) require a higher return for holding a more risky asset.

Since beta reflects asset-specific sensitivity to non-diversifiable, i.e. market risk, the market as a whole, by definition, has a beta of one. Stock market indices are frequently used as local proxies for the market - and in that case (by definition) have a beta of one. An investor in a large, diversified portfolio (such as a mutual fund) therefore expects performance in line with the market.

\section{Literature review}

Stehle (1997) and Stulz (1995a, 1995b, 1999) argue that using a domestic market index is only appropriate for an asset traded in a closed, national financial market. Although equilibrium international asset pricing models are multifactor in general, if the purchasing power parity (PPP) condition holds, then the single factor CAPM equation can be adapted to a international context for asset in the global market portfolio, as discussed in Stulz (1995c). We emphasize the difference between the domestic and global CAPMs by

$\mathrm{Ri}=\mathrm{Rf}+\hat{\mathrm{a}}[\mathrm{Rm}-\mathrm{Rf}](1)$

Where, $\mathrm{Ri}$ is the expected rate of return for asset $\mathrm{i}$ in a specific pricing currency, $\mathrm{Rf}$ is the nominal rate of return on an asset that is risk free \& denominated in the pricing Currency, $\hat{a}$ is the beta of asset i's

Vol 5 Issue 1 March 2012 returns against the unhedged stock market returns, with returns computed in pricing currency, $\mathrm{Rm}$ is the required rate of return in the pricing currency on the unhedged stock market portfolio, and Rm - Rf is the risk premium on the unhedged stock market portfolio.

Karolyi and Stulz (2003) point out that only in special case in which $\hat{a}_{i G}$ equals $\hat{a}_{i D} \hat{a}_{D G}$ does the global CAPM result in the same expected return as the domestic CAPM, i.e., when an asset's global beta is equal to its domestic beta times the global beta of the domestic market portfolio. Generally, this condition does not hold. Instead, when $\hat{a}_{i G}$ is greater than $\hat{a}_{i D} \hat{a}_{D G}$ the domestic CAPM is likely to underestimate the asset's expected return relative to the global CAPM, because there is more global systematic risk in the asset's returns than is accounted for by the domestic market index. Similarly, when $\hat{a}_{i G}$ is less than $\hat{a}_{i D} \hat{a}_{D G}$ the domestic CAPM is likely to overestimate the asset's expected return relative to the global CAPM, because the asset has less global systematic risk in its returns than is accounted for by the domestic market index.

Stehle (1977) reports empirical support for the CAPM over the version in realized returns for the stocks from 1956 to 1975. Harvey's (1991) study provides further empirical support of the pricing of equities. Black (1993) asserts that the issue of whether stocks should be used in CAPM applications is not yet settled. However, given the significant financial markets, Stulz (1995a, 1995b, 1999) advocates the use of global version. In contrast to Stehle's (1977) findings, Griffin (2002) reports that for the period between 1981 and 1995, a three - factor (Fama- French) domestic model had lower pricing errors for firms than did an analogous Three factor world version. His results indicate that a pricing model is a better fit with realized return data.

Campbell's (1996) empirical analysis of a multifactor pricing model finds that the single factor CAPM is a good approximate model for stock and bond prices, since the additional factors (returns to human capital and changes in expected market return) are highly correlated with the market index returns. $\mathbf{~ N g}$ (2003) reaches a similar conclusion in the context of the CAPM, with the additional factors of risk and shifts in expected market returns and expected changes. Therefore, we only examine the 
Single- factor CAPM. Griffin (2002) does not report results on compared to world Single- Factor (Market index) models. Griffin reported that the version of the single factor model had lower pricing error.

A stock could be the preferred benchmark for investors with a significant 'home bias', as in the Cooper and Kaplanis (2000) model of partially integrated stock markets. However, we do not know whether the popularity of the CAPM among firms is for this reason.

Finally, Robert S. Harris, Dev R Mishra (2003) advocates that Single factor CAPM has a better fit but at the end they gave a lead in their article that after extending our study to smaller companies, we might shed more light on CAPM.

Empirical tests comparing pricing model usually rely on realized returns. However, Elton (1999) points out that ex ante estimates of expected returns are more desirable. We obtain ex ante expected return estimates through discounted cash flow (DCF) models, as in a number of prior studies, including Claus and Thomas (2001), Fama and French (2002), and others discussed below.

In contrast to research that uses realized returns, almost all of the studies using ex ante expected return estimates find an empirical relation between expected return and beta risk, despite differences in approaches and time periods. Harris and Marston (1992) and Harris (1993) report a significant relation between ex ante expected return estimates and 0 betas for a sample of stocks in the 1982-1987 periods. At the same time they confirm the findings of previous empirical studies of no significant relation between realized returns and betas.

The results of Gebhardt, Lee, and Swaminathan (2001) provide the only exception that we know of to a positive empirical relation between ex ante expected return and beta risk estimates. Their study, which uses IBES forecasts and a clean surplus residual income valuation model, reports no significant association between their ex ante expected returns estimates and betas for a sample of stocks from the period 1979-1995.
There is some controversy about IBES forecasts. La Porta (1996) asserts that analysts' growth forecasts tend to be too extreme, but Lee, Myers, and Swaminathan (1999) find that IBES forecasts improve their intrinsic value estimates over forecasts based on a time series model.

\section{Methodology}

Our sample comprises S\&P CNX NIFTY companies over the period $2005-2010$.In this paper five years nifty stocks of 10 companies has been taken for testing relevance of CAPM analysis. The main objective of this paper is to test the CAPM model and to use the CAPM for the selection of securities and portfolios using SML.

\section{Expected return Estimation:}

For each year from 2005 through 2010, we calculated an expected return estimate for S\&P CNX Nifty stock for which data is available. The firm is eliminated if the standard deviation around the mean forecast exceeds $20 \%$, or if there are not sufficient historical returns for the prior 24 months to perform the beta estimations. The dividend and other firm specific information is obtained by the various sources like Capitaline and Prowees databases.

The expected rates of returns are estimated by using the constant dividend growth model.

$\mathrm{K}_{\mathrm{i}}=\mathrm{D}_{1 \mathrm{i}} / \mathrm{P}_{0 \mathrm{i}}+\mathrm{G}_{\mathrm{i}}$

Where $\mathrm{Ki}$ is the ex ante expected rate of return (cost of Equity) estimate for the company I, D1i is the dividend per share expected to be received at time 1 , $\mathrm{PO} \mathrm{i}$ is the current price per share, and $\mathrm{Gi}$ the expected growth rate in dividends per share, which are calculated by taking the EBIT growth rate for the 10 years.

This study is a 'test' of the underlying model and the empirical constructs used. Therefore this cannot be concluded whether rejection is due to failure of the model or of the empirical proxies.

Finally, using the widespread use of the CAPM, the conflicting empirical results on the impact of using a risk or returns of stocks warrants additional study 
using a variety of approaches. Furthermore, additional empirical results on the constant growth model, given its longstanding history and continued use, could be useful.

\section{Security Market Line:}

There is a simple linear relationship between the expected return and standard deviation in efficient portfolios. Typically, the expected return and standard deviation for individual securities will be below the CML, reflecting the inefficiency of undiversified holdings. Further, such points would be found throughout the feasible region with no well-defined relationship between their expected return and standard deviation. However, there is a linear relationship between their expected return and their covariance with the market portfolio. This relationship, called the Security Market Line,

In words, the SML relationship says:

Expected return on security $i=$ Risk-free return + (Price per unit of risk) Risk

The price per unit of risk is : $\frac{\varepsilon\left(\mathrm{R}_{\mathrm{m}}\right)-\mathrm{R}_{\mathrm{f}}}{\mathrm{o}^{2}{ }_{\mathrm{m}}}$

The risk measure of risk is: óim

In equation, the risk of a security is expressed in terms of its covariance with the market portfolio, óim. We can find a standardized measure of systematic risk, popularly called beta by (â) taking advantage of the relationship:

$$
\hat{a} i=\frac{\text { ó }_{\mathrm{m}}}{\mathrm{o}_{\mathrm{m}}^{2}}
$$

â $i$ reflects the slope of a linear regression relationship in which the return on security $i$ is regressed on the return on the market portfolio.

Thus, the SML is popularly expressed as

$$
E(R)=R f+[E(R M)-R f] \text { âi }
$$

In words, the SML relationship says:

Expected return Risk- free Market

Beta of on security $\mathrm{i}=$ return + risk premium $\mathrm{X}$ security $\mathrm{i}$ The SML which reflects the expected return- beta relationship is shown in The Security Market Line.
In this the slope of the SML is the market risk premium.

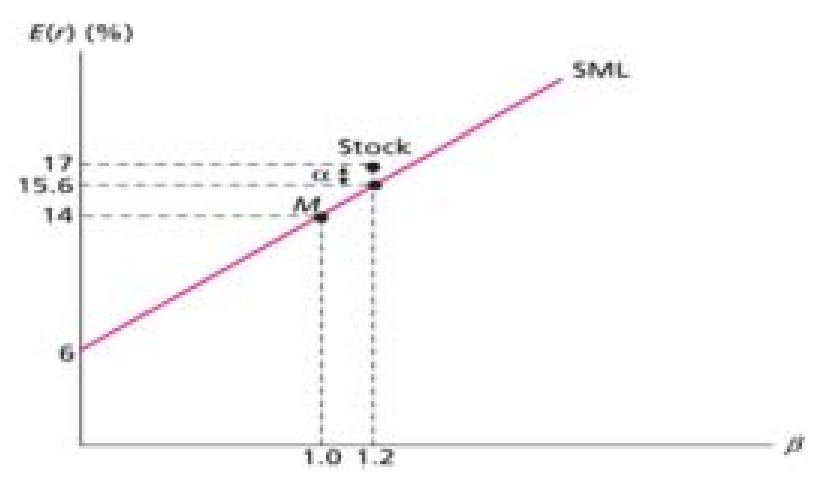

Assets which are fairly priced plot exactly on the SML. Underpriced securities (such as P) plot above the SML, whereas overpriced securities (such as $\mathrm{O}$ ) plot below the SML. The difference between the actual expected return on a security and its fair return as per the SML is called the security's alpha, denoted by á.

The SML which reflects the expected return-beta relationship is shown in The Security Market Line. In this the slope of the SML is the market risk premium.

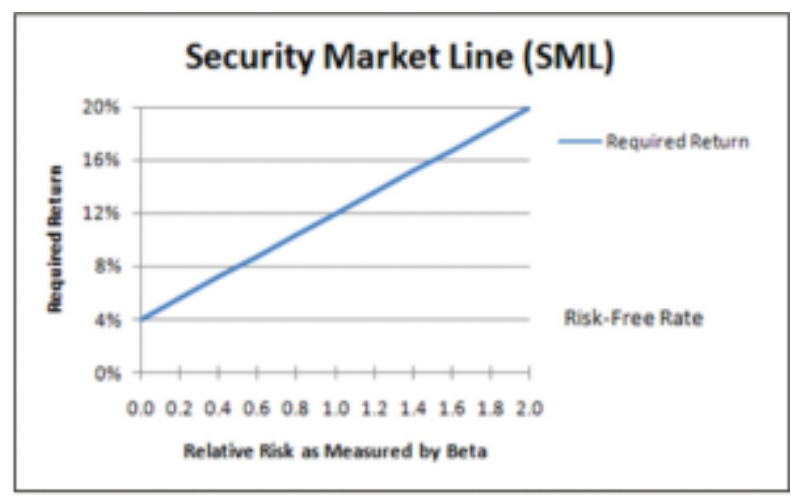

\section{Evaluation of securities:}

Relative attractiveness of the security can be found out with the help of security market line. Stocks with high risk factor are expected to yield more return and vice-versa. But the investor would be interested in knowing whether the security is offering return more or less proportional to its risk. 


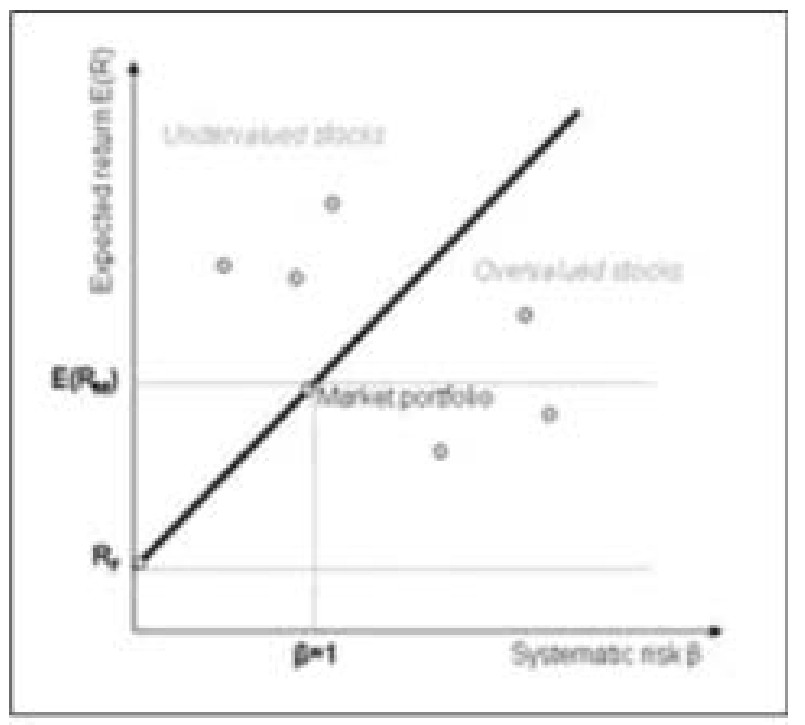

The above figure provides an explanation for the evaluation. There are points in the diagram. The stocks above the SML yield higher returns for the same level of risk. They are underpriced compared to their beta value.

\section{Market imperfection and SML:}

Information regarding the share price and market condition may not be immediately available to all investors. Imperfect information may affect the valuation of securities. In a market with perfect information, all securities should lie on SML. Market imperfections affect the width of the SML to a band. If imperfections are more, the width also would be larger.

To use CAPM to estimate a firm's cost of equity, a time varying approach is applied to estimate betas and market risk premium. The equity betas are estimated for a particular year with yearly excess returns (the stock return minus 91 days Treasury bill ( $T$ - bill) return) for five years prior to the year for which the expected return is estimated. The equity betas for all companies are estimated by using an ordinary least squares (OLS) of the excess returns on excess stock market returns. The yearly stock returns are obtained from 2005 through 2010 from CAPITALINE database. T Bill returns are obtained from the website of Reserve Bank of India. S\&P CNX Nifty Stock is used as the stock market. The ten Securities for five years taken from NSE stocks is used as individual portfolio or securities. The data for the ten securities are obtained from the website of NSE.

We first turn each stocks expected return estimate into a risk premium estimate by subtracting the yield on the 91 days T-bond. Then we aggregate the stocks risk premium estimates with value weighting, producing a portfolio risk premium estimate. For the CAPM, we value-weight the firms domestic beta estimates into a portfolio domestic beta estimate for the year. Since the portfolio risk premium should be equal to the portfolio beta times the market risk premium, the domestic market risk premium estimate for the month is found implicitly by dividing the portfolio risk premium estimate by the portfolio domestic beta estimate. To ensure a fair comparison between the risk and returns, we use an analogous procedure (each year) to estimate the implicit stock market risk premium from the portfolio risk premium estimate and the portfolio's beta estimate. In other words, we estimate the stock market risk premium by assuming that the CAPM is valid for the average stock, and estimate the stock market risk premium by assuming that the CAPM is valid for the average stock By design, this approach implies that the average difference between the model estimates and the estimates is zero for both CAPM versions.

We then investigate how much variation exists for individual firms between the risk premium estimates and the corresponding estimates of CAPM version. For each year from 31-Mar-2005 until 31-Mar- 2010, we analyze each stock as follows. We begin by using the stock's beta and the market risk premium estimates to find the firm's risk premium estimate under the CAPM, We also estimate the stock's risk premium under the CAPM with the stock's beta and the market risk premium estimates. We then compare the risk premium estimate for the stock with the risk premium 
Closing values of securities for 5 years

\begin{tabular}{|c|c|c|c|c|c|c|c|c|c|c|c|}
\hline YEAR & Nifty & HDFC & $\begin{array}{c}\text { INFOSYS } \\
\text { TECH }\end{array}$ & BHEL & ITC & $\begin{array}{c}\text { TATA } \\
\text { MOTORS }\end{array}$ & $M \& M$ & Reliance & SBI & TCS & $\begin{array}{l}\text { AXIS } \\
\text { BANK }\end{array}$ \\
\hline $\begin{array}{l}\text { 31-Mar- } \\
05\end{array}$ & 2035.65 & 1207 & 2996.85 & 1387.05 & 142.1 & 653.4 & 511.6 & 889.3 & 908.15 & 1702.85 & 286.95 \\
\hline $\begin{array}{l}\text { 31-Mar- } \\
06\end{array}$ & 3402.55 & 1626.9 & 2241.8 & 2299.35 & 176.1 & 900.6 & 908.45 & 1270.15 & 1245.6 & 1222 & 469.6 \\
\hline $\begin{array}{l}\text { 31-Mar- } \\
07\end{array}$ & 3821.55 & 2877.7 & $\$ 1769.9$ & 2589.75 & 209.45 & 741.9 & 861.95 & 2882.7 & 2371.15 & 1077.4 & 970.45 \\
\hline $\begin{array}{l}\text { 31-Mar- } \\
08\end{array}$ & 4734.5 & 1486.4 & 1115.45 & 1362.6 & 171.7 & 159.85 & 274.5 & 1232.75 & 1288.8 & 477.9 & 504.7 \\
\hline $\begin{array}{l}\text { 31-Mar- } \\
09\end{array}$ & 3020.95 & 2675.8 & 2601.1 & 2403.3 & 250.8 & 791.55 & 1080.85 & 1090.55 & 2269 & 750.25 & 989.2 \\
\hline $\begin{array}{l}\text { 31-Mar- } \\
10\end{array}$ & 5249.1 & 728.35 & 3442.75 & 2323.7 & 174.65 & 1308.35 & 778.2 & 1058.7 & 2811.9 & 1165.65 & 1350.1 \\
\hline
\end{tabular}

Data Analysis for selected NIFTY stocks

\begin{tabular}{|lllllll|}
\hline Securities & Rf & $\mathbf{a}$ & $\mathbf{E}(\mathbf{R m})$-Rf & Expected(Ri) & Estimated(Ri) & Remarks \\
HDFC & 4.566 & 0.8473 & 136.3497 & 70.5644 & 120.0951 & Overpriced \\
Infosys Tech & 4.566 & 0.7785 & 136.3497 & 82.3244 & 110.7142 & Overpriced \\
BHEL & 4.566 & 0.1964 & 136.3497 & 104.0814 & 31.3451 & Underpriced \\
TC & 4.566 & 0.3726 & 136.3497 & 40.5474 & 55.3699 & Overpriced \\
TATAMOTORS & 4.566 & 1.9483 & 136.3497 & 402.2299 & 270.2161 & Underpriced \\
M\&M & 4.566 & 1.6537 & 136.3497 & 270.0493 & 230.0475 & Underpriced \\
Reliance & 4.566 & 0.1333 & 136.3497 & 98.0913 & 22.7468 & Underpriced \\
SBI & 4.566 & 0.2571 & 136.3497 & 181.8555 & 39.6215 & Underpriced \\
TCS & 4.566 & 0.189 & 136.3497 & 16.6429 & 30.3361 & Overpriced \\
AXIS BANK & 4.566 & 0.192 & 136.3497 & 254.7953 & 30.7451 & Underpriced \\
\hline
\end{tabular}

Following securities are advisable for investors to buy because they are underpriced:
1) BHEL
2) Tata Motors
3) $M \& M$
4) Reliance
5) $\mathrm{SBI}$
6) AXIS BANK 
Following securities are advisable for investors to sell because they are overpriced.
1) HDFC
2) Infosys Tech
3) ITC
4) TCS

\section{Present Validity of CAPM :}

The CAPM is greatly appealing at an intellectual level, logical and rational. The basic assumptions on which the model is built raise, some doubts in the minds of the investors. Yet, investment analysts have been more creative in adapting CAPM for their uses

1. The CAPM focuses on the market risk, makes the investors to think about the riskiness of the assets in general. CAPM provides a basic concept which is truly of fundamental value.

2. The CAPM has been useful in the selection of securities and portfolios. Securities with higher returns are considered to be undervalued and attractive for buy. The below normal expected return yielding securities are considered to be overvalued and suitable for sale.

3. In the CAPM, it has been assumed that investors consider only the market risk. Given the estimate of the risk free rate, the beta of the firm, stock and the required market rate of return, one can find out the expected returns for a firm's security. This expected return can be used as an estimate of the cost of retained earnings.

\section{Conclusion}

We find that the CAPM has a better fit with the dispersion of expected return estimates, overall and for all samples the previous researches also emphasis on this fact and in this study we also found that the CAPM has the less risk premium differences for all the Five years. While the SML model provides a better fit of our data, the relatively small empirical difference between the models suggests that for estimating the Expected rate of return for the securities, the choice between the overpriced or under priced securities may not be material issues for many large firms.

\section{References}

- Black, Fischer., Michael C. Jensen, and Myron Scholes (1972). The Capital Asset Pricing Model: Some Empirical Tests, pp. 79-121 in M. Jensen ed., Studies in the Theory of Capital Markets. New York: Praeger Publishers.

- Fama, Eugene F. (1968). Risk, Return and Equilibrium: Some Clarifying Comments. Journal of Finance Vol. 23, No. 1, pp. 29-40. Markowitz, Harry M. (1999). The early history of portfolio theory: 1600-1960, Financial Analysts Journal, Vol. 55, No. 4

- Mehrling, Perry (2005). Fischer Black and the Revolutionary Idea of Finance. Hoboken: John Wiley \& Sons, Inc.

- Mossin, Jan. (1966). Equilibrium in a Capital Asset Market, Econometrica, Vol. 34, No. 4, pp. 768-783.

- Ross, Stephen A. (1977). The Capital Asset Pricing Model (CAPM), Short-sale Restrictions and Related Issues, Journal of Finance, 32 (177)

- Rubinstein, Mark (2006). A History of the Theory of Investments. Hoboken: John Wiley \& Sons, Inc.

- Sharpe, William F. (1964). Capital asset prices: A theory of market equilibrium under conditions of risk, Journal of Finance, 19 (3), 425-442

- $\quad$ Stone, Bernell K. (1970) Risk, Return, and Equilibrium: A General Single-Period Theory of Asset Selection and Capital-Market Equilibrium. Cambridge: MIT Press.

- Tobin, James (1958). Liquidity preference as behavior towards risk, The Review of Economic Studies, 25

- Treynor, Jack L. (1961). Market Value, Time, and Risk. Unpublished manuscript.

- Treynor, Jack L. (1962). Toward a Theory of Market Value of Risky Assets. Unpublished manuscript. A final version was published in 1999, in Asset Pricing and Portfolio Performance: Models, Strategy and Performance Metrics. Robert A. Korajczyk (editor) London: Risk Books, pp. 15-22. 
- Mullins, David W. (1982). Does the capital asset pricing model work?, Harvard Business Review, January-February 1982, 105-113.

- Treynor, Jack L. (1962). Toward a Theory of Market Value of Risky Assets. Unpublished manuscript. A final version was published in 1999, in Asset Pricing and Portfolio Performance: Models, Strategy and Performance Metrics. Robert A. Korajczyk (editor) London: Risk Books, pp. 15-22.
- Mullins, David W. (1982). Does the capital asset pricing model work?, Harvard Business Review, January-February 1982, 105-113.

- Prince,Kudzai Hwenjere. (2010). Capital Markets in the World and Raising markets in Zimbabwe, National University of Science Technology. Bcom Banking,2010 